\title{
Correlation of HAMP gene polymorphisms and expression with the susceptibility and length of hospital stays in Taiwanese children with Kawasaki disease
}

\author{
Ying-Hsien Huang1,*, Kuender D. Yang ${ }^{2, *}$, Yu-Wen Hsu ${ }^{3,4, *}$, Hsing-Fang Lu, ${ }^{4,5}$, Henry \\ Sung-Ching Wong ${ }^{4,6}$, Hong-Ren $\mathrm{Yu}^{1}$, Hsing-Chun Kuo ${ }^{7,8,9}$, Fu-Chen Huang ${ }^{1}$, Mao-Hung \\ Lo $^{1}$, Kai-Sheng Hsieh ${ }^{1}$, Su-Fen Chen ${ }^{11}$, Wei-Chiao Chang ${ }^{4,6,10}$ and Ho-Chang Kuo ${ }^{1,6}$ \\ ${ }^{1}$ Department of Pediatrics and Kawasaki Disease Center, Kaohsiung Chang Gung Memorial Hospital and Chang Gung \\ University College of Medicine, Kaohsiung, Taiwan \\ ${ }^{2}$ Institute of Biomedical Sciences, Mackay Medical College, New Taipei City, Department of Pediatrics, Mackay Memorial \\ Hospital, Taipei, and Institute of Clinical Medicine, National Yang Ming University, Taipei, Taiwan \\ ${ }^{3}$ The Ph.D. Program for Translational Medicine, College of Medical Science and Technology, Taipei Medical University and \\ Academia Sinica, Taipei, Taiwan \\ ${ }^{4}$ Department of Clinical Pharmacy, Taipei Medical University, Taipei, Taiwan \\ ${ }^{5}$ Department of Pharmacy, Taipei Medical University-Shuang Ho Hospital, Taipei, Taiwan \\ ${ }^{6}$ Master's Program for Clinical Pharmacogenomics and Pharmacoproteomics, School of Pharmacy, Taipei Medical University, \\ Taipei, Taiwan \\ ${ }^{7}$ Department of Nursing, Chang Gung University of Science and Technology, Chiayi, Taiwan \\ ${ }^{8}$ Research Center for Industry of Human Ecology and Research Center for Chinese Herbal Medicine, College of Human \\ Ecology, Chang Gung University of Science and Technology, Taoyuan, Taiwan \\ ${ }^{9}$ Chronic Diseases and Health Promotion Research Center, CGUST, Chiayi, Taiwan \\ ${ }^{10}$ Center for Biomarkers and Biotech Drugs, Kaohsiung Medical University, Kaohsiung, Taiwan \\ ${ }^{11}$ Department of Pharmacy, St Vincent Medical Center, Los Angeles, California, USA \\ *These authors contributed equally to this work
}

Correspondence to: Ho-Chang Kuo, email: erickuo48@yahoo.com.tw Wei-Chiao Chang, email: wcc@tmu.edu.tw

Keywords: hepcidin, genetic polymorphism, kawasaki disease

Received: August 26, $2016 \quad$ Accepted: March 27, $2017 \quad$ Published: May 08, 2017

Copyright: Huang et al. This is an open-access article distributed under the terms of the Creative Commons Attribution License 3.0 (CC BY 3.0), which permits unrestricted use, distribution, and reproduction in any medium, provided the original author and source are credited.

\section{ABSTRACT}

Kawasaki disease (KD) is a form of systemic vasculitis. Regarding its pathogenesis, HAMP gene encoding hepcidin, which is significant for iron metabolism, has a vital function. In this study, we recruited a total of 381 KD patients for genotyping. Data from 997 subjects (500 subjects from cohort 1; 497 subjects from cohort 2) were used for analysis. Using TaqMan allelic discrimination, we determined five tag SNPs (rs916145, rs10421768, rs3817623, rs7251432, and rs2293689). Treatment outcome data related to such clinical phenotypes as coronary artery lesions (CAL), coronary artery aneurysms (CAA), and intravenous immunoglobulin (IVIG) effects were also collected. Furthermore, we measured plasma hepcidin levels with an enzyme-linked immunosorbent assay. We found that HAMP gene polymorphism (rs7251432, and rs2293689) was significantly correlated with KD risk and that plasma hepcidin levels both before and after IVIG treatment had a significantly positive correlation with length of hospital stays $(R=0.217, p=0.046$ and $R=0.381$, $p<0.0001$, respectively). In contrast, plasma hepcidin levels has a negative correlation with KD patients' albumin levels $(R=-0.27, p<0.001)$ prior to IVIG treatment. This study's findings indicate that HAMP might have a role in the disease susceptibility, as well as its expressions correlated length of hospital stays, and albumin levels in Taiwanese children with KD. 


\section{INTRODUCTION}

A form of acute vasculitis, KD (Kawasaki disease) affects various systems, most often in children under the age of five years old [1]. KD affects the vascular system in both small and medium-sized blood vessels and especially in coronary arteries [2]. As a result, nearly $20 \%$ of children who do not receive treatment suffer a coronary artery aneurysm [3]. The most serious complication of $\mathrm{KD}$ is the development of coronary artery lesions (CAL), including myocardial infarctions, coronary artery fistula formations [4], coronary artery dilatations, and coronary artery aneurysms (CAA) [5].

In addition to the diagnostic criteria by the American Heart Association and the American Academy of Pediatrics, such nonspecific clinical symptoms as uveitis, aseptic meningitis, gallbladder hydrops, urethritis, arthralgia, arthritis, hypoalbuminemia, liver function impairment anemia, and heart failure have also been found in KD sufferers [6], with anemia being the most commonly found [7-10]. Hepcidin, a protein for iron regulation, reduces iron level by inhibiting intestinal iron absorption and keeping iron storage in macrophages, leading to impaired hemoglobin synthesis [11]. It is essential not only for iron metabolism but also for the pathogenesis of inflammation anemia [11]. Unusually high levels of hepcidin have been found in anemia in various inflammatory disorders, including autoimmune diseases [12, 13], infections [14, 15], critical illnesses [16, 17], and obesity [18]. In our previous study, we also found that abnormally high levels of hepcidin could impair iron metabolism and subsequently correlate with reduced hemoglobin levels in KD patients $[19,20]$. Furthermore, in that study, the changes in hepcidin levels after intravenous immunoglobulin (IVIG) treatment were correlated with CAL and IVIG resistance in KD patients [19]. An increasing amount of evidence has shown that iron levels are associated with coronary artery disease [21, 22] and vasculitis [23, 24]. Moreover, as KD occurs more commonly in Asian populations than European populations [2], we also reported that the $\mathrm{C}$ allele of rs916145 in the HAMP promoter area has a higher frequency of developing biliary atresia, which is consistent with the low incidence of biliary atresia in European populations [25]. However, no correlation studies between HAMP and KD have yet been reported. In this study, we aim to determine the role of HAMP in children's susceptibility to $\mathrm{KD}, \mathrm{CAL}$ formation, and CAA, as well as IVIG treatment responses, lengths of hospital stays, and albumin levels.

\section{RESULTS}

\section{Basal characteristics of KD patients}

The KD patients' basal characteristics for genotyping and plasma hepcidin assay are summarized in Tables 1 and 2, respectively. This study was consisted of
$381 \mathrm{KD}$ patients and 997 controls (500 subjects data from cohort 1; 497 subjects data from cohort 2). Male subjects accounted for $66.8 \%$ of KD patients and $56 \%$ of healthy subjects. A total of $49(12.9 \%) \mathrm{KD}$ patients did not respond to their initial IVIG treatment, $64(16.8 \%)$ KD patients developed CAL, and 16 (4.2\%) patients developed CAA. The subjects' HAMP genotype distribution agreed with the Hardy-Weinberg equilibrium (Supplementary Table 1).

\section{Association study of $H A M P$ gene polymorphisms for susceptibility to $\mathrm{KD}$}

We investigated the correlations between HAMP genetic polymorphisms and susceptibility for KD. As shown in Table 3, rs2293689 of HAMP significantly correlated with the risk of KD under the allelic models $(p=0.0410)$. Application of second cohort, another polymorphism, rs7251432, was identified to associate with the susceptibility for KD under the recessive model $(p=0.0315)$. (Table 3).

\section{Lack of correlation between $H A M P$ polymorphisms and CAL formation, IVIG treatment, and aneurysm formation in $\mathrm{KD}$ patients}

We also tested whether the HAMP polymorphisms correlated with the clinical phenotypes, but none of the polymorphisms had an association with CAL, CAA, or response to IVIG treatment (Tables 4, 5, and 6).

\section{Correlation between length of hospital stays and hepcidin levels in KD patients}

In a prior study, we showed that the changes in hepcidin levels were related to the development of CAL and the response for IVIG treatment in KD patients [19]. In this study, we showed that longer hospital stays were observed in KD patients with CAL than in those without CAL $(p=0.005)$ (Figure 1). Furthermore, we confirmed using linear regression modeling that plasma hepcidin levels both before and after receiving IVIG treatment were positively correlated with patients' length of hospital stays $(R=0.217, p=0.046$ and $R=0.381, p<0.0001$, respectively), as shown in Figure 2.

\section{Correlation between AST, ALT, albumin, and hepcidin levels in KD patients}

KD patients often present with hepatitis and jaundice [26], and since hepatocytes are the major producer of hepcidin, that could be directly related to the reason for modified hepcidin expression in KD patients. Furthermore, lower albumin levels were correlated with a resistance to intravenous immunoglobulin treatment and CAL formation [27-29]. We found that plasma hepcidin levels were 
Patients with KD

$N=381$

Male gender, No. (\%)

$247(66.8 \%)$

Mean (SD) age (years)

$1.7 \pm 0.08$

$0-11$

Age range (years)

CAL formation

$64(16.8 \%)$

$16(4.2 \%)$

Aneurysm formation $49(12.9 \%)$

IVIG resistance

CAL: coronary artery lesions; IVIG: intravenous immunoglobulin; SD: standard deviation.

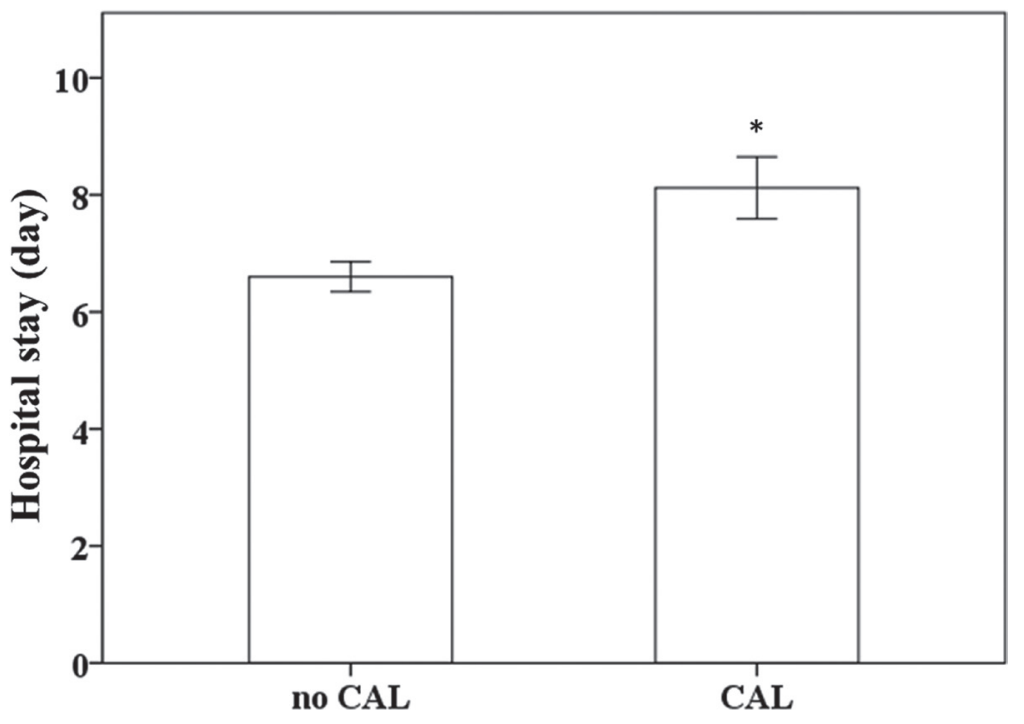

Figure 1: Comparison of KD patients' length of hospital stays. Data are presented as mean \pm standard error. * indicates $p<0.05$ between groups. KD indicates Kawasaki disease, CAL indicates coronary artery lesions.
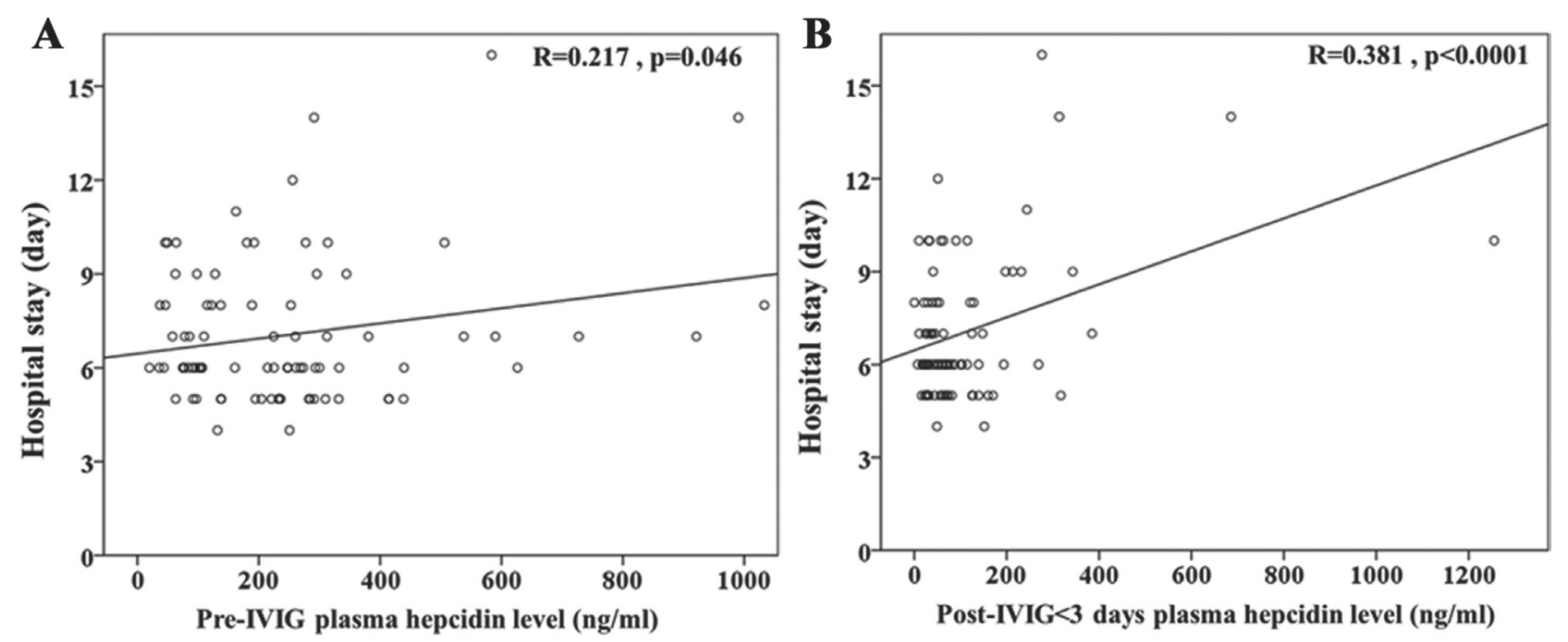

Figure 2: Univariate analysis illustrates that plasma hepcidin levels both (A) before and (B) after IVIG treatment were positively correlated with patients' length of hospital stays $(R=0.217, p=0.046$, and $R=0.381, p<0.0001$, respectively). 


\begin{tabular}{|c|c|c|c|}
\hline Characteristics & pre-IVIG & post-IVIG $<3$ days & $p$-value \\
\hline & $N=85$ & & \\
\hline Mean (SEM), age (m) & $21.6 \pm 1.8$ & & \\
\hline Gender (male : female) & $53: 32$ & & \\
\hline CAL formation & $25(29 \%)$ & & \\
\hline IVIG resistance & & & \\
\hline WBC (1000/uL) & $13.8 \pm 0.5$ & $10.6 \pm 0.5$ & $<0.0001$ \\
\hline CRP (mg/L) & $87.2 \pm 6.6$ & $46.6 \pm 6$ & $<0.0001$ \\
\hline Albumin (g/dL) & $3.1 \pm 0.06$ & $2.8 \pm 0.01$ & 0.007 \\
\hline GOT (U/L) & $62.1 \pm 7.3$ & $43.4 \pm 9.4$ & 0.103 \\
\hline GPT (U/L) & $77.1 \pm 9.2$ & $42.3 \pm 9.4$ & 0.007 \\
\hline
\end{tabular}

CAL: coronary artery lesions; IVIG: intravenous immunoglobulin; CRP: C-reactive protein; GOT: Glutamic Oxaloacetic Transaminase; GPT: Glutamic Pyruvic Transaminase.

negatively correlated with albumin $(\mathrm{R}=-0.27, p<0.001)$ prior to IVIG treatment in KD patients (Figure 3).

\section{DISCUSSION}

We reported herein that HAMP correlated with KD patients' disease susceptibility and length of hospital stays. Furthermore, rs2293689 of HAMP is an important marker with a significant correlation with KD risk. Plasma hepcidin levels in the KD patients both before and after IVIG treatment were positively correlated with patients' length of hospital stays. In contrast, plasma hepcidin was negatively correlated with albumin before KD patients received IVIG treatment.
While there are many elevated inflammatory mediators in KD patients' peripheral blood, no particular biomarker can be used to successfully predict the susceptibility, morbidity, prognosis, and treatment response of KD. The susceptible gene(s) and mechanisms of immunopathogenesis for KD also need to be clarified. In our recently study, we uncovered KD patients showed remarkably hypomethylation at the gene promoters of toll like receptors (TLRs), especially TLR 1, 2, 4, 6, 8, and 9, and increased these TLR mRNA expressions [30]. Interestingly, TLR4 dependent macrophage signaling is associated with coronary arterial disease [31] and a TLR4 agonist has been shown to stimulate hepcidin expression [32]. Moreover, hepcidin not only controls iron metabolism

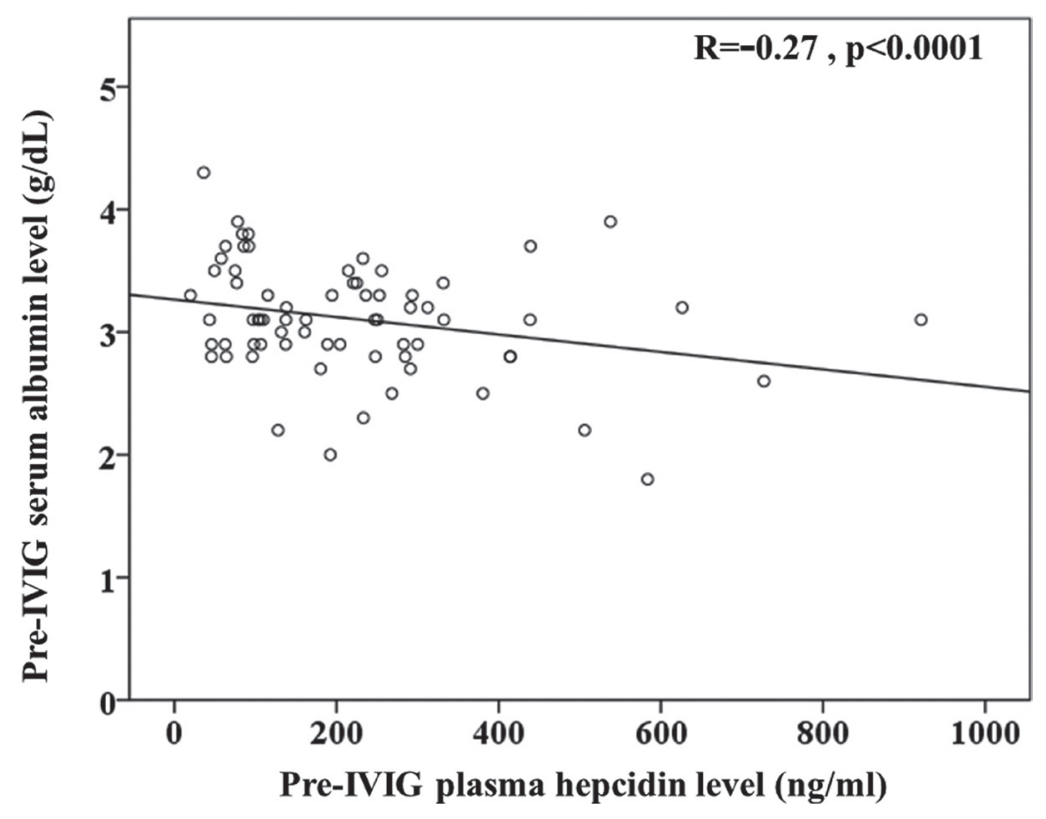

Figure 3: Univariate analysis illustrates that plasma hepcidin was negatively correlated with (c) albumin $(\mathrm{R}=-0.27, \mathrm{p}<0.001)$ prior to IVIG treatment in KD patients. 
Table 3: Genotype and allele frequencies of the $H A M P$ gene in controls and patients with Kawasaki disease

\begin{tabular}{|c|c|c|c|c|c|c|c|c|}
\hline & Genotype & $\begin{array}{l}\text { Case }(\%) \\
(n=381)\end{array}$ & $\begin{array}{c}\text { Control } \\
\text { cohort } 1 \\
(\%)(n=497)\end{array}$ & $\begin{array}{c}\text { Control } \\
\text { cohort } 2(\%) \\
(n=500)\end{array}$ & $\begin{array}{c}\text { Cohort } 1 \\
\text { Recessive } \\
P \text { Value }\end{array}$ & $\begin{array}{l}\text { Allelic } \\
P \text { Value }\end{array}$ & $\begin{array}{c}\text { Cohort } 2 \\
\text { Recessive } \\
P \text { Value }\end{array}$ & $\begin{array}{l}\text { Allelic } \\
P \text { Value }\end{array}$ \\
\hline \multirow[t]{3}{*}{ rs916145 } & $\mathrm{CC}$ & $46(13.1)$ & $60(12.2)$ & $71(14.2)$ & 0.7108 & 0.6652 & 0.6481 & 0.4768 \\
\hline & CG & $158(45.0)$ & $219(44.7)$ & $231(46.2)$ & & & & \\
\hline & GG & $147(41.9)$ & $211(43.1)$ & 198 (39.6) & & & & \\
\hline \multirow[t]{3}{*}{ rs10421768 } & GG & $0(0.0)$ & $0(0.0)$ & $0(0.0)$ & 1.0000 & 0.3270 & 1.000 & 0.4533 \\
\hline & $\mathrm{AG}$ & $3(0.8)$ & $8(1.6)$ & $7(1.4)$ & & & & \\
\hline & AA & $354(99.2)$ & 489 (98.4) & 493 (98.6) & & & & \\
\hline \multirow[t]{3}{*}{ rs3817623 } & $\mathrm{TT}$ & $2(0.6)$ & $2(0.5)$ & $1(0.2)$ & 0.8828 & 0.3129 & 03745 & 0.9983 \\
\hline & GT & $30(8.5)$ & $45(11.0)$ & $46(9.2)$ & & & & \\
\hline & GG & $322(90.9)$ & $363(88.5)$ & $453(90.6)$ & & & & \\
\hline \multirow[t]{3}{*}{ rs 7251432} & GG & $67(18.8)$ & $77(16.1)$ & $67(13.4)$ & 0.3120 & 0.1672 & $0.0315 *$ & 0.0939 \\
\hline & $\mathrm{AG}$ & $163(45.8)$ & $212(44.5)$ & $243(48.6)$ & & & & \\
\hline & AA & $126(35.4)$ & $188(39.4)$ & $190(38.0)$ & & & & \\
\hline \multirow[t]{3}{*}{ rs 2293689} & TT & $2(0.6)$ & $4(1.3)$ & $2(0.4)$ & 0.3333 & $0.0410 *$ & 0.7366 & 0.8016 \\
\hline & $\mathrm{CT}$ & $44(12.3)$ & $54(17.0)$ & $60(12.0)$ & & & & \\
\hline & $\mathrm{CC}$ & $312(87.1)$ & $260(81.7)$ & $438(87.6)$ & & & & \\
\hline
\end{tabular}

*Significant $(P<0.05)$ values are in bold.

but also plays a role in the pathogenesis of inflammation anemia [11]. Since anemia is often found in KD patients [19], we also indicated that higher hepcidin levels cause iron deficiency in the serum, thus reducing the availability of iron for erythropoiesis [20]. Furthermore, hepcidin associated iron homeostasis influences the ability of the macrophage polarization program [33] and aberrant activation and infiltration of macrophages is thought to be involved in the formation of arteritis in KD [34]. Moreover, we have shown in a recent study that high-dose aspirin significantly hinders the decrease of hepcidin levels and may be associated with a decrease in hemoglobin during the acute phase of KD [35].

Hepatocytes are the major producer of hepcidin. Since KD patients often present with hepatitis and jaundice [26], that may be one of the main reasons for modified hepcidin expression in KD patients. In fact, various studies have shown that higher AST and ALT levels and lower albumin levels were correlated with IVIG treatment resistance and CAL formation [27-29]. We further demonstrated that changes in hepcidin levels after patients received IVIG treatment were correlated with IVIG resistance and CAL formation [19]. In this study, we uncovered that plasma hepcidin was positively correlated with AST and ALT and negatively correlated with albumin prior to IVIG treatment in KD patients. In a recent study, plasma hepcidin was observed to increase significantly in ICU patients when compared with controls and was the highest in septic patients [36]. Hepcidin- induced low iron levels were also associated with both the short-term and long-term survival of critically ill patients [37]. Furthermore, Lin et al. identified hemoglobin as a useful marker for differentiating KD shock syndrome from toxic shock syndrome in a pediatric intensive care unit [38]. Therefore, the plasma hepcidin is greater in KD shock syndrome than in toxic shock syndrome. Therefore, the hepcidin and hemoglobin levels in KD can possibly be utilized clinically as a differential tool in the future. Based on the results in this study, we propose that hepcidin likely plays an important role in the pathogenesis and disease outcomes of KD patients. In the future, researcher should investigate the molecular machinery of hepcidin in KD and might unlock the mystery of KD.

However, this study still has limitations. The correlation coefficient between plasma hepcidin and several markers for KD severity were statistically significant but had values less than 0.4 , thus potentially limiting the clinical application. Although HAMP demonstrated a borderline significance in the risk of KD in a Taiwanese population, clinical samples of a second population should be considered to confirm this significance.

In short, we reported herein that $H A M P$ polymorphism might have a role in the disease susceptibility, as well as its expressions correlated with disease susceptibility, length of hospital stays, and albumin levels. This study provides a potential prognosis biomarker for Taiwanese children with $\mathrm{KD}$. 
Table 4: Genotype and allele frequencies of $H A M P$ gene in Kawasaki disease patients with or without coronary artery lesion formation

\begin{tabular}{|c|c|c|c|c|c|c|c|c|c|c|}
\hline & Genotype & $\begin{array}{l}\text { CAL } 2(\%) \\
(n=64)\end{array}$ & $\begin{array}{l}\text { Without }(\%) \\
(n=310)\end{array}$ & Allele & $\begin{array}{l}\text { CAL } 2(\%) \\
(n=64)\end{array}$ & $\begin{array}{l}\text { Without }(\%) \\
(n=310)\end{array}$ & $\begin{array}{l}\text { Genotype } \\
p \text {-value }\end{array}$ & $\begin{array}{l}\text { Dominant } \\
p \text {-value }\end{array}$ & $\begin{array}{l}\text { Recessive } \\
p \text {-value }\end{array}$ & $\begin{array}{l}\text { Allelic } \\
p \text {-value }\end{array}$ \\
\hline \multirow[t]{3}{*}{ rs916145 } & $\mathrm{CC}$ & $10(18.2)$ & $36(12.3)$ & $\mathrm{C}$ & $47(42.7)$ & $202(34.6)$ & 0.2696 & 0.1501 & 0.2403 & 0.1026 \\
\hline & $\mathrm{CG}$ & $27(49.1)$ & $130(44.5)$ & G & $64(57.3)$ & $382(65.4)$ & & & & \\
\hline & GG & $18(32.7)$ & $126(43.2)$ & & & & & & & \\
\hline \multirow[t]{3}{*}{ rs10421768 } & GG & $0(0.0)$ & $0(0.0)$ & G & $1(0.9)$ & $2(0.3)$ & - & 0.4275 & - & 0.4285 \\
\hline & $\mathrm{AG}$ & $1(1.7)$ & $2(0.7)$ & A & 115 (99.1) & 588 (99.7) & & & & \\
\hline & AA & $57(98.3)$ & $293(99.3)$ & & & & & & & \\
\hline \multirow[t]{3}{*}{ rs3817623 } & TT & $0(0.0)$ & $2(0.7)$ & $\mathrm{T}$ & $5(4.3)$ & $28(4.8)$ & 0.8158 & 0.9447 & 0.5273 & 0.8222 \\
\hline & GT & $5(8.6)$ & $24(8.2)$ & G & $111(95.7)$ & $556(95.2)$ & & & & \\
\hline & GG & $53(91.4)$ & $266(91.1)$ & & & & & & & \\
\hline \multirow[t]{3}{*}{ rs7251432 } & GG & $8(13.6)$ & $56(19.1)$ & G & $44(37.3)$ & 247 (42.2) & 0.5787 & 0.5414 & 0.3130 & 0.3278 \\
\hline & $\mathrm{AG}$ & $28(47.4)$ & $135(46.1)$ & A & $74(62.7)$ & $339(57.8)$ & & & & \\
\hline & AA & $23(39.0)$ & $102(34.8)$ & & & & & & & \\
\hline \multirow[t]{3}{*}{ rs2293689 } & $\mathrm{TT}$ & $0(0.0)$ & $2(0.7)$ & $\mathrm{T}$ & $4(3.3)$ & $43(7.3)$ & 0.2682 & 0.1127 & 0.5176 & 0.1013 \\
\hline & $\mathrm{CT}$ & $4(6.6)$ & $39(13.3)$ & $\mathrm{C}$ & 118 (96.7) & $543(92.7)$ & & & & \\
\hline & $\mathrm{CC}$ & $57(93.4)$ & $252(86.0)$ & & & & & & & \\
\hline
\end{tabular}

Table 5: Genotype and allele frequencies of the $H A M P$ gene in Kawasaki disease patients with aneurysm or without aneurysm

\begin{tabular}{|c|c|c|c|c|c|c|c|c|c|c|}
\hline & Genotype & $\begin{array}{c}\text { Aneurysm } \\
(\%)(n=16)\end{array}$ & $\begin{array}{l}\text { Without (\%) } \\
\quad(n=362)\end{array}$ & Allele & $\begin{array}{l}\text { Aneurysm } \\
(\%)(n=16)\end{array}$ & $\begin{array}{l}\text { Without (\%) } \\
\quad(n=362)\end{array}$ & $\begin{array}{l}\text { Genotype } \\
p \text {-value }\end{array}$ & $\begin{array}{c}\text { Dominant } \\
p \text {-value }\end{array}$ & $\begin{array}{l}\text { Recessive } \\
p \text {-value }\end{array}$ & $\begin{array}{c}\text { Allelic } \\
p \text {-value }\end{array}$ \\
\hline \multirow[t]{3}{*}{ rs916145 } & $\mathrm{CC}$ & $1(7.1)$ & 45 (13.4) & $\mathrm{C}$ & $10(35.7)$ & $240(35.6)$ & 0.6052 & 0.6332 & 0.4999 & 0.9908 \\
\hline & CG & $8(57.1)$ & $150(44.5)$ & G & $18(64.3)$ & $434(64.4)$ & & & & \\
\hline & GG & $5(35.7)$ & $142(42.1)$ & & & & & & & \\
\hline \multirow[t]{3}{*}{ rs10421768 } & GG & $0(0.0)$ & $0(0.0)$ & G & $0(0.0)$ & $3(0.4)$ & - & 0.7253 & - & 0.7258 \\
\hline & AG & $0(0.0)$ & $3(0.9)$ & A & $28(100.0)$ & $683(99.6)$ & & & & \\
\hline & AA & $14(100.0)$ & $340(99.1)$ & & & & & & & \\
\hline \multirow[t]{3}{*}{ rs3817623 } & $\mathrm{TT}$ & $0(0.0)$ & $2(0.6)$ & $\mathrm{T}$ & $2(6.7)$ & $32(4.7)$ & 0.7571 & 0.5534 & 0.7655 & 0.6255 \\
\hline & GT & $2(13.3)$ & $28(8.3)$ & G & $28(93.3)$ & $646(95.3)$ & & & & \\
\hline & GG & $13(86.7)$ & 309 (91.1) & & & & & & & \\
\hline \multirow[t]{3}{*}{ rs7251432 } & GG & $3(20.0)$ & 64 (18.8) & G & $14(46.7)$ & $283(41.5)$ & 0.7621 & 0.4702 & 0.9049 & 0.5740 \\
\hline & AG & $8(53.3)$ & $155(45.4)$ & A & $16(53.3)$ & $399(58.5)$ & & & & \\
\hline & AA & $4(26.7)$ & $122(35.8)$ & & & & & & & \\
\hline \multirow[t]{3}{*}{ rs2293689 } & $\mathrm{TT}$ & $0(0.0)$ & $2(0.6)$ & $\mathrm{T}$ & $0(0.0)$ & $48(7.0)$ & 0.2909 & 0.1161 & 0.7590 & 0.1208 \\
\hline & $\mathrm{CT}$ & $0(0.0)$ & 44 (12.9) & $\mathrm{C}$ & $32(100.0)$ & $636(93.0)$ & & & & \\
\hline & $\mathrm{CC}$ & $16(100.0)$ & $296(86.5)$ & & & & & & & \\
\hline
\end{tabular}

\section{PATIENTS AND METHODS}

\section{Patients}

The Institutional Review Board of Chang Gung Memorial Hospital approved our study, and we obtained written informed consent from the parents or guardians of all the participating children. We recruited $381 \mathrm{KD}$ patients (Table 1) for this study, and all of them were first treated with one dose of intravenous immunoglobulin (IVIG) $(2 \mathrm{~g} / \mathrm{kg}$ ) over $12 \mathrm{~h}$. We took two sets of blood samples: one within $24 \mathrm{~h}$ prior to IVIG treatment (pre-IVIG) and the other within 3 days following IVIG treatment (post-IVIG). We excluded any patients with symptoms that either did not correspond to the KD criteria or had experienced acute fever for less than 5 days. All patients were subjected to two-dimensional, pulse Doppler and color flow imaging at least three times within 8 weeks from the onset of the illness. If a patient was observed to have abnormal coronary arteries, an echocardiographic follow-up was 
Table 6: Genotype and allele frequencies of the $H A M P$ gene in Kawasaki disease patients that respond or do not respond to intravenous immunoglobulin treatment

\begin{tabular}{|c|c|c|c|c|c|c|c|c|c|c|}
\hline & Genotype & $\begin{array}{l}\text { Resistant }(\%) \\
\quad(n=49)\end{array}$ & $\begin{array}{c}\text { Responsive }(\%) \\
(n=326)\end{array}$ & Allele & $\begin{array}{l}\text { Resistant }(\%) \\
\quad(n=49)\end{array}$ & $\begin{array}{c}\text { Responsive }(\%) \\
\quad(n=326)\end{array}$ & $\begin{array}{c}\text { Genotype } \\
p \text {-value }\end{array}$ & $\begin{array}{c}\text { Dominant } \\
p \text {-value }\end{array}$ & $\begin{array}{c}\text { Recessive } \\
p \text {-value }\end{array}$ & $\begin{array}{l}\text { Allelic } \\
p \text {-value }\end{array}$ \\
\hline \multirow[t]{3}{*}{ rs916145 } & $\mathrm{CC}$ & $5(10.6)$ & $40(13.2)$ & $\mathrm{C}$ & $36(38.3)$ & $212(35.1)$ & 0.3306 & 0.2444 & 0.6199 & 0.5467 \\
\hline & CG & $26(55.3)$ & $132(43.7)$ & G & $58(61.7)$ & 392 (64.9) & & & & \\
\hline & GG & $16(34.0)$ & $130(43.1)$ & & & & & & & \\
\hline \multirow[t]{3}{*}{ rs 10421768} & GG & $0(0.0)$ & $0(0.0)$ & G & $0(0.0)$ & $3(0.5)$ & - & 0.5068 & - & 0.5077 \\
\hline & $\mathrm{AG}$ & $0(0.0)$ & $3(1.0)$ & A & $45(100.0)$ & $615(99.5)$ & & & & \\
\hline & AA & $45(100.0)$ & $306(99.0)$ & & & & & & & \\
\hline \multirow[t]{3}{*}{ rs 3817623} & $\mathrm{TT}$ & $0(0.0)$ & $2(0.7)$ & $\mathrm{T}$ & $6(6.4)$ & $28(4.6)$ & 0.4642 & 0.3464 & 0.5777 & 0.4504 \\
\hline & GT & $6(12.8)$ & $24(7.9)$ & G & 88 (93.6) & $582(95.4)$ & & & & \\
\hline & GG & $41(87.2)$ & $279(91.5)$ & & & & & & & \\
\hline \multirow[t]{3}{*}{ rs 7251432} & GG & $7(15.2)$ & $60(19.5)$ & G & $37(40.2)$ & 258 (41.9) & 0.7292 & 0.9020 & 0.4911 & 0.7624 \\
\hline & AG & $23(50.0)$ & $138(44.8)$ & A & $55(59.8)$ & $358(58.1)$ & & & & \\
\hline & AA & $16(34.8)$ & $110(35.7)$ & & & & & & & \\
\hline \multirow[t]{3}{*}{ rs2293689 } & $\mathrm{TT}$ & $0(0.0)$ & $2(0.7)$ & $\mathrm{T}$ & $7(7.3)$ & $41(6.7)$ & 0.7618 & 0.7184 & 0.5749 & 0.8236 \\
\hline & $\mathrm{CT}$ & 7 (14.6) & $37(12.0)$ & $\mathrm{C}$ & 89 (92.7) & $573(93.3)$ & & & & \\
\hline & $\mathrm{CC}$ & $41(85.4)$ & $268(87.3)$ & & & & & & & \\
\hline
\end{tabular}

scheduled every 3 to 6 months for one year and then once a year afterwards until the affected coronary arteries returned to normal, as reported in our previous studies $[29,39]$. This current study carried out said the aforementioned echocardiography using a SONOS 5500 or 7500 cardiac scanner (Philips, Andover, MA, USA) and 5- to 8-MHz sector phased array transducers in order to visualize the diameters of both the right and left coronary arteries on the parasternal short-axis view of the aorta [4]. Pursuant to the guidelines of Japan's Ministry of Health, a CAL is considered a coronary artery if it has an internal diameter more than $3 \mathrm{~mm}$ (or $4 \mathrm{~mm}$, if the patient was older than 5 years old) or if a segment has a diameter that is at least 1.5 times that of a contiguous segment, as observed on an echocardiogram. KD patients with coronary artery ectasia or dilatation that disappeared within the first 8 weeks after the onset of the illness were considered as having transient ectasia instead of CAL [40, 41]. We further classified coronary arteries based on whether aneurysms were present using the criteria published by the JCS Joint Working Group. A CAA (including medium and large aneurysms) was defined as a coronary artery with an internal diameter of at least $4 \mathrm{~mm}$ or, in children older than 5 years old, a segment with an internal diameter at least 1.5 times that of a contiguous segment as observed through echocardiography [40, 41]. A patient was considered to have responded to IVIG treatment if his/her fever abated $48 \mathrm{~h}$ after completing IVIG treatment and they had no recurrence of fever (defined as a temperature $>38^{\circ} \mathrm{C}$ ) for at least 7 days afterwards, as well as visible improvement or normalization of inflammation [10, 29]. We also examined the plasma hepcidin in 85 patients with KD (Table 2) before and after they were treated with IVIG. The blood samples were immediately placed in tubes that already had heparin, while the other plasma aliquots were stored at $-80^{\circ} \mathrm{C}$ until they were assayed.

\section{DNA extraction}

We treated the obtained blood cells with a $0.5 \%$ SDS lysis buffer and then protease $\mathrm{K}(1 \mathrm{mg} / \mathrm{ml})$ for 4 hours at $60^{\circ} \mathrm{C}$ to digest nuclear proteins. All DNA was extracted using a Gentra extraction kit, which was followed by $70 \%$ alcohol precipitation.

\section{Genotyping}

We selected five tagging SNPs of HAMP (rs916145, rs 10421768, rs3817623, rs 7251432, and rs2293689) with a minimum allelic frequency of $1 \%$ in the Han Chinese population from the HapMap database (http://hapmap. ncbi.nlm.nih.gov/). All HAMP gene polymorphisms were found in the introns. We carried out genotyping using a TaqMan Allelic Discrimination Assay (Applied Biosystems, Foster City, CA, USA). PCR was performed quickly with a 96-well microplate in an ABI 9700 Thermal Cycler using the following thermal cycling conditions: denaturation at $95^{\circ} \mathrm{C}$ for 10 minutes, followed by 40 cycles of denaturation at $92^{\circ} \mathrm{C}$ for 15 seconds each, and then annealing and extension at $60^{\circ} \mathrm{C}$ for $1 \mathrm{~min}$ as previously described [42]. We used System SDS software version 1.2.3 to quantify and analyze fluorescence. The average genotyping success rate of our laboratory was $95.7 \%$; therefore, the genotyping data of some subjects were unavailable. The genotype data of the 500 control subjects were obtained from Taiwan's Bio-Bank. 


\section{Measurement of cytokines by enzyme-linked immunoassay (ELISA)}

The ELISA kits that we used for plasma hepcidin-25 were commercially available competitive assays with synthetic hepcidin (Bachem Biosciences, St. Helens, United Kingdom, Catalog Number: S-1337), and we used the performance protocol described in one of our previous studies [19].

\section{Statistical analysis}

All data in this study are presented as mean \pm standard error. The genotypes and allele frequencies that correlated with KD susceptibility and disease outcomes (CAL formation, IVIG treatment response, and aneurysm) were analyzed using the Chi-square test, which was then used with 1 degree of freedom to carry out the Hardy-Weinberg equilibrium. Changes between the values before and after IVIG treatment were evaluated with a paired-sample $t$-test. Two-sided $p$-values $<0.05$ were considered statistically significant. All statistical analyses were performed using SPSS version 22.0 for Windows (SPSS software, Inc., Chicago, IL, USA) and JMP 9.0 for Windows.

\section{Abbreviations}

$\mathrm{CAA}=$ coronary artery aneurysms, $\mathrm{CAL}=$ coronary artery lesions, IVIG $=$ intravenous immunoglobulin, $\mathrm{KD}=$ Kawasaki disease, $\mathrm{SN} P=$ single nucleotide polymorphism.

\section{CONFLICTS OF INTEREST}

The authors hereby state that they have no financial interests to disclose in relation to this article.

\section{GRANT SUPPORT}

This study was partly supported by a grant from the Ministry of Science and Technology (MOST: 105-2314-B-182-050-MY3), the Ministry of Health and Welfare (PMRPG8E0011), and Chang Gung Memorial Hospital CMRPG8F1911，CMRPG8F1921，CMRPG 8F1931, CMRPG8F1941 and in Taiwan. The funders had no role in study design, data collection and analysis, decision to publish, or preparation of the manuscript.

\section{REFERENCES}

1. Kawasaki T, Kosaki F, Okawa S, Shigematsu I, Yanagawa H. A new infantile acute febrile mucocutaneous lymph node syndrome (MLNS) prevailing in Japan. Pediatrics. 1974; 54:271-276.
2. Wang CL, Wu YT, Liu CA, Kuo HC, Yang KD. Kawasaki disease: infection, immunity and genetics. Pediatr Infect Dis J. 2005; 24:998-1004.

3. Newburger JW, Takahashi M, Burns JC, Beiser AS, Chung KJ, Duffy CE, Glode MP, Mason WH, Reddy V, Sanders SP and et al. The treatment of Kawasaki syndrome with intravenous gamma globulin. N Engl J Med. 1986; 315:341-347.

4. Liang CD, Kuo HC, Yang KD, Wang CL, Ko SF. Coronary artery fistula associated with Kawasaki disease. American heart journal. 2009; 157:584-588.

5. Newburger JW, Takahashi M, Gerber MA, Gewitz MH, Tani LY, Burns JC, Shulman ST, Bolger AF, Ferrieri P, Baltimore RS, Wilson WR, Baddour LM, Levison ME, et al. Diagnosis, treatment, and long-term management of Kawasaki disease: a statement for health professionals from the Committee on Rheumatic Fever, Endocarditis, and Kawasaki Disease, Council on Cardiovascular Disease in the Young, American Heart Association. Pediatrics. 2004; 114:1708-1733.

6. Newburger JW, Takahashi M, Gerber MA, Gewitz MH, Tani LY, Burns JC, Shulman ST, Bolger AF, Ferrieri P, Baltimore RS, Wilson WR, Baddour LM, Levison ME, et al. Diagnosis, treatment, and long-term management of Kawasaki disease: a statement for health professionals from the Committee on Rheumatic Fever, Endocarditis and Kawasaki Disease, Council on Cardiovascular Disease in the Young, American Heart Association. Circulation. 2004; 110:2747-2771.

7. Alves NR, Magalhaes CM, Almeida Rde F, Santos RC, Gandolfi L, Pratesi R. Prospective study of Kawasaki disease complications: review of 115 cases. Rev Assoc Med Bras. 2011; 57:295-300.

8. Fukushige J, Takahashi N, Ueda Y, Ueda K. Incidence and clinical features of incomplete Kawasaki disease. Acta Paediatr. 1994; 83:1057-1060.

9. Kuo HC, Wang CL, Liang CD, Yu HR, Chen HH, Wang L, Yang KD. Persistent monocytosis after intravenous immunoglobulin therapy correlated with the development of coronary artery lesions in patients with Kawasaki disease. J Microbiol Immunol Infect. 2007; 40:395-400.

10. Kuo HC, Yang KD, Liang CD, Bong CN, Yu HR, Wang L, Wang CL. The relationship of eosinophilia to intravenous immunoglobulin treatment failure in Kawasaki disease. Pediatr Allergy Immunol. 2007; 18:354-359.

11. Fleming RE, Bacon BR. Orchestration of iron homeostasis. The New England journal of medicine. 2005; 352:1741-1744.

12. Abdel-Khalek MA, El-Barbary AM, Essa SA, Ghobashi AS. Serum hepcidin: a direct link between anemia of inflammation and coronary artery atherosclerosis in patients with rheumatoid arthritis. J Rheumatol. 2011; 38:2153-2159.

13. Demirag MD, Haznedaroglu S, Sancak B, Konca C, Gulbahar O, Ozturk MA, Goker B. Circulating hepcidin in 
the crossroads of anemia and inflammation associated with rheumatoid arthritis. Intern Med. 2009; 48:421-426.

14. Armitage AE, Eddowes LA, Gileadi U, Cole S, Spottiswoode N, Selvakumar TA, Ho LP, Townsend AR, Drakesmith H. Hepcidin regulation by innate immune and infectious stimuli. Blood. 2011; 118:4129-4139.

15. de Mast Q, Nadjm B, Reyburn H, Kemna EH, Amos B, Laarakkers CM, Silalye S, Verhoef H, Sauerwein RW, Swinkels DW and van der Ven AJ. Assessment of urinary concentrations of hepcidin provides novel insight into disturbances in iron homeostasis during malarial infection. J Infect Dis. 2009; 199:253-262.

16. Isoda $\mathrm{M}$, Hanawa $\mathrm{H}$, Watanabe $\mathrm{R}$, Yoshida $\mathrm{T}$, Toba $\mathrm{K}$, Yoshida K, Kojima M, Otaki K, Hao K, Ding L, Tanaka K, Takayama T, Kato K, et al. Expression of the peptide hormone hepcidin increases in cardiomyocytes under myocarditis and myocardial infarction. J Nutr Biochem. 2010; 21:749-756.

17. Sihler KC, Raghavendran K, Westerman M, Ye W, Napolitano LM. Hepcidin in trauma: linking injury, inflammation, and anemia. J Trauma. 2010; 69:831-837.

18. del Giudice EM, Santoro N, Amato A, Brienza C, Calabro P, Wiegerinck ET, Cirillo G, Tartaglione N, Grandone A, Swinkels DW, Perrone L. Hepcidin in obese children as a potential mediator of the association between obesity and iron deficiency. J Clin Endocrinol Metab. 2009; 94:5102-5107.

19. Kuo HC, Yang YL, Chuang JH, Tiao MM, Yu HR, Huang LT, Yang KD, Chang WC, Lee CP, Huang YH. Inflammation-induced hepcidin is associated with the development of anemia and coronary artery lesions in Kawasaki disease. J Clin Immunol. 2012; 32:746-752.

20. Huang YH, Kuo HC, Huang FC, Yu HR, Hsieh KS, Yang YL, Sheen JM, Li SC, Kuo HC. Hepcidin-Induced Iron Deficiency Is Related to Transient Anemia and Hypoferremia in Kawasaki Disease Patients. International journal of molecular sciences. 2016; 17.

21. Kaluza J, Larsson SC, Hakansson N, Wolk A. Heme iron intake and acute myocardial infarction: A prospective study of men. International journal of cardiology. 2014; 172:155-160.

22. Hunnicutt J, He K, Xun P. Dietary iron intake and body iron stores are associated with risk of coronary heart disease in a meta-analysis of prospective cohort studies. The Journal of nutrition. 2014; 144:359-366.

23. Oliveira R, Napoleao P, Banha J, Paixao E, Bettencourt A, da Silva BM, Pereira D, Barcelos F, Teixeira A, Patto JV, Viegas-Crespo AM, Costa L. Crosstalk between inflammation, iron metabolism and endothelial function in Behcet's disease. Clinical hemorheology and microcirculation. 2014; 56:175-185

24. Mascitelli L, Goldstein MR. Hereditary hemochromatosis, iron, hepcidin, and coronary heart disease. Medical hypotheses. 2014; 82:402-403.
25. Huang YH, Huang CC, Chuang JH, Hsieh CS, Lee SY, Chen CL. Upstream stimulatory factor 2 is implicated in the progression of biliary atresia by regulation of hepcidin expression. J Pediatr Surg. 2008; 43:2016-2023.

26. Chen CJ, Huang FC, Tiao MM, Huang YH, Lin LY, Yu HR, Yang KD, Huang YC, Chen CC, Chang WC, Kuo HC. Sonographic gallbladder abnormality is associated with intravenous immunoglobulin resistance in Kawasaki disease. ScientificWorldJournal. 2012; 2012:485758.

27. Baek JY, Song MS. Meta-analysis of factors predicting resistance to intravenous immunoglobulin treatment in patients with Kawasaki disease. Korean journal of pediatrics. 2016; 59:80-90.

28. Yilmazer MM, Oner T, Gokalp S, Doksoz O, Guven B, Vupa Cilengiroglu O, Mese T, Tavli V. Risk factors for persistence of coronary artery abnormalities in Turkish children with Kawasaki disease. The Turkish journal of pediatrics. 2015; 57:248-253.

29. Kuo HC, Liang CD, Wang CL, Yu HR, Hwang KP, Yang KD. Serum albumin level predicts initial intravenous immunoglobulin treatment failure in Kawasaki disease. Acta Paediatr. 2010; 99:1578-1583.

30. Huang YH, Li SC, Huang LH, Chen PC, Lin YY, Lin CC, Kuo HC. Identifying genetic hypomethylation and upregulation of toll-like receptors in Kawasaki disease. Oncotarget. 2017; 8:11249-11258. doi: 10.18632/oncotarget.14497.

31. Habib A, Polavarapu R, Karmali V, Guo L, Van Dam R, Cheng Q, Akahori H, Saeed O, Nakano M, Pachura K, Hong CC, Shin E, Kolodgie F, et al. Hepcidin-ferroportin axis controls toll-like receptor 4 dependent macrophage inflammatory responses in human atherosclerotic plaques. Atherosclerosis. 2015; 241:692-700.

32. Pietrangelo A, Dierssen U, Valli L, Garuti C, Rump A, Corradini E, Ernst M, Klein C, Trautwein C. STAT3 is required for IL-6-gp130-dependent activation of hepcidin in vivo. Gastroenterology. 2007; 132:294-300.

33. Agoro R, Mura C. Inflammation-induced up-regulation of hepcidin and down-regulation of ferroportin transcription are dependent on macrophage polarization. Blood Cells Mol Dis. 2016; 61:16-25.

34. Takahashi K, Oharaseki T, Yokouchi Y. Pathogenesis of Kawasaki disease. Clin Exp Immunol. 2011; 164:20-22.

35. Kuo HC, Lo MH, Hsieh KS, Guo MM, Huang YH. HighDose Aspirin Is Associated with Anemia and Does Not Confer Benefit to Disease Outcomes in Kawasaki Disease. PLoS One. 2015; 10:e144603.

36. Tacke F, Nuraldeen R, Koch A, Strathmann K, Hutschenreuter G, Trautwein C, Strnad P. Iron Parameters Determine the Prognosis of Critically Ill Patients. Critical care medicine. 2016; 44:1049-1058.

37. Lasocki S, Gaillard T, Rineau E. Iron is essential for living! Crit Care. 2014; 18:678.

38. Lin YJ, Cheng MC, Lo MH, Chien SJ. Early Differentiation of Kawasaki Disease Shock Syndrome and Toxic Shock 
Syndrome in a Pediatric Intensive Care Unit. Pediatr Infect Dis J. 2015; 34:1163-1167.

39. Kuo HC, Onouchi Y, Hsu YW, Chen WC, Huang JD, Huang YH, Yang YL, Chao MC, Yu HR, Juan YS, Kuo CM, Yang KD, Huang JS, et al. Polymorphisms of transforming growth factor-beta signaling pathway and Kawasaki disease in the Taiwanese population. J Hum Genet. 2011; 56:840-845.

40. Shulman ST, De Inocencio J, Hirsch R. Kawasaki disease. Pediatr Clin North Am. 1995; 42:1205-1222.
41. Kuo HC, Yu HR, Juo SH, Yang KD, Wang YS, Liang CD, Chen WC, Chang WP, Huang CF, Lee CP, Lin LY, Liu YC, Guo YC, et al. CASP3 gene single-nucleotide polymorphism (rs72689236) and Kawasaki disease in Taiwanese children. J Hum Genet. 2011; 56:161-165.

42. Huang YH, Hsu YW, Lu HF, Wong HS, Yu HR, Kuo HC, Huang FC, Chang WC, Kuo HC. Interferon-gamma Genetic Polymorphism and Expression in Kawasaki Disease. Medicine. 2016; 95:e3501. 